\title{
Simulation of Coupled Heat and Moisture transfer in Air-conditioned Buildings
}

\author{
Rafik BELARBI, Menghao QIN, and Abdelkarim AÏT-MOKHTAR
}

(LEPTAB, Université de La Rochelle, La Rochelle, France. Email: mqin@univ-lr.fr)

\begin{abstract}
The simultaneous heat and moisture transfer in the building envelope has an important influence on the indoor environment and the overall performance of buildings. In this paper, a model for predicting whole building heat and moisture transfer was presented. Both heat and moisture transfer in the building envelope and indoor air were simultaneously considered; their interactions were modeled. The coupled model takes into account the main hygrothermal effects, like moisture sources and sinks inside the room, moisture transfer through the envelope, vapor sorptiondesorption at the exterior and interior wall surfaces, heat sources and sinks inside the room, heat input from the envelope, the solar energy input through walls and windows, and hygrothermal sources or sinks due to the air-conditioning system. The new model was implemented in MATLAB-Simulink, and was validated by using a series of testing and validation tools.
\end{abstract}

Keywords simultaneous heat and moisture transfer, simulation, air-conditioning building

\section{Introduction}

Moisture accumulation within building components can lead to poor thermal performance of the envelope, metal corrosion and structure deterioration. In addition to the building's construction damage, moisture migrating through building envelopes has significant effect on indoor air humidity and air-conditioning loads, especially latent cooling load. Moisture problems in buildings are results of simultaneous heat and moisture transfer in building envelopes and indoor air. Many mathematical models ${ }^{[1]}$ for moisture transfer in buildings have been suggested to predict the moisture transfer effect on indoor air humidity and building energy consumption. The same holds for the thermal modeling of whole buildings where several validated computer codes exist, e.g. EnergyPlus HAM-VIE, TRNSYS, and DOE-2 etc. However, few existing model takes into account the hygrothermal interactions between the building envelope and the indoor air.

The objective of this paper is to develop a model for predicting transient thermal and moisture transfer behavior in air-conditioned buildings including building envelopes and indoor air. The whole building heat and moisture transfer model takes into account the main hygrothermal effects: moisture sources and sinks inside a room, moisture input from the envelope, diffusion and vapor sorption-desorption at the exterior and interior wall surfaces, heat sources and sinks inside the room, heat input from the envelope, the solar energy input through walls and windows and hygrothermal sources and sinks due to air-conditioning systems etc. The coupled system model is implemented in MATLAB-Simulink, and is also validated by using a series of published testing tools. 


\section{Modeling of whole building heat and moisture transfer 2.1 Coupled heat and moisture transfer in the wall}

\subsubsection{Governing equations}

In the present study, vapor content and temperature are chosen as principal driving potentials. The phase-change occurring within porous materials acts as a heat source or sink, which results in the coupled relationship between moisture transfer and heat transfer. The heat of absorption or desorption is generally one of the sources or sinks as well. One-dimensional governing equations with coupled temperature and moisture for a multi-layer porous wall are considered, and the effect of the absorption or desorption heat is added. The moisture diffusivity is temperature and moisture dependent. A local thermodynamic equilibrium between the fluid and the porous matrix is assumed, and the equations are as follows ${ }^{[1]}$ :

$$
\begin{aligned}
& \rho C_{P} \cdot \frac{\partial T}{\partial t}=\frac{\partial}{\partial x}\left(\lambda \frac{\partial T}{\partial x}\right)+\rho C_{m}\left(\sigma h_{l v}+\gamma\right) \frac{\partial v}{\partial t} \\
& \rho C_{m} \frac{\partial v}{\partial t}=\frac{\partial}{\partial x}\left(\delta \frac{\partial v}{\partial x}\right)+\frac{\partial}{\partial x}\left(\varepsilon \delta \frac{\partial T}{\partial x}\right)
\end{aligned}
$$

where, $T$ is the temperature [K], and $v$ is the vapor content $\left[\mathrm{kg} \mathrm{m}^{-3}\right], \lambda$ is the thermal conductivity [W m$\left.{ }^{-1} \mathrm{~K}^{-1}\right], \delta$ is the moisture diffusion coefficient $\left[\mathrm{m}^{2} \mathrm{~s}^{-1}\right], C_{p}$ and $C_{m}$ are the heat and moisture capacities of the material $\left[\mathrm{J} \mathrm{kg}^{-1} \mathrm{~K}^{-1}\right],\left[\mathrm{m}^{3} \mathrm{~kg}^{-1}\right]$ respectively, $\rho$ is the material density $\left[\mathrm{kg} \mathrm{m}^{-3}\right], h_{l v}$ is the heat of evaporative phase-change $\left[\mathrm{J} \mathrm{kg}^{-1}\right], \gamma$ represents the heat of absorption or desorption $[\mathrm{kJ}$ $\left.\mathrm{kg}^{-1}\right], \varepsilon$ is the thermogradient coefficient $\left[\mathrm{kg} \mathrm{m}^{-3} \mathrm{~K}^{-1}\right]$, and $\sigma$ is the ratio of the vapor diffusion coefficient to the coefficient of total moisture diffusion.

Eq. (1) expresses the balance of thermal energy within the body; the last term in this equation represents the heat sources or heat sinks due to liquid-to-vapor phase-change and to the adsorption or desorption process. Eq. (2) expresses the balance of moisture within the medium; the last term in this equation represents the moisture source or moisture sink related to the temperature gradient.

\subsubsection{Boundary conditions at the wall surfaces}

The model assumes that the external wall surface is exposed to convective heat and moisture exchange with outdoor air, incident solar radiation, and long wave radiation, transfer of latent heat, air and rain. All outdoor influences are lumped into equivalent outdoor surface air temperature ${ }^{[2]}$. The internal wall surface is exposed to convective heat and moisture exchange, long wave radiation with other surfaces, and transfer of latent heat with inner air. All these influences are lumped into equivalent indoor surface air temperature ${ }^{[2]}$.

Generally, the coupled system for temperature and moisture potential can be handled by both analytical and numerical approaches, depending on the specific problem considered. When the material properties are constant, the coupled linear equations can be solved by the analytical method proposed by $\mathrm{QIN}^{[1]}$. In the paper, the hygrothermal diffusion coefficients of porous building materials are variables and dependent on temperature and moisture conditions. The coupled nonlinear model for the hygrothermal transfer in the walls is numerically solved in MATLABSimulink. 


\subsection{Heat and moisture balance of the air-conditioned space}

The temperature and relative humidity of the air-conditioned space is calculated accounting for the heat and moisture gains through the building envelope, internal sources and HVAC equipment etc.

The heat balance model assumes that: (1) uniform air temperature, (2) all radiation is distributed in such a way that all surfaces absorb the same amount per unit of surface area, (3) the surface coefficients for convection and radiation are the same for all surfaces. The heat balance can be described with the following equation.

$$
\begin{aligned}
& \rho \cdot C_{P} \cdot V \frac{\partial T}{\partial t}=\sum_{j} A_{j} \alpha_{j}\left(T_{j}-T_{i}\right)+Q_{\text {sol. }}+Q_{i n} \\
& +n \cdot V \cdot \rho \cdot C_{P} \cdot\left(T_{o}-T_{i}\right)+Q_{v e n .}
\end{aligned}
$$

Where, $\rho$ is the density of the air $\left[\mathrm{kg} \mathrm{m}^{-3}\right], \alpha_{j}$ is the heat transfer coefficient $\left[\mathrm{W} \mathrm{m} \mathrm{m}^{-1}\right], T_{a}$ is the exterior air temperature $[\mathrm{K}], T_{j}$ is the surface temperature $[\mathrm{K}], T_{i}$ is the indoor air temperature $[\mathrm{K}], t$ presents time $[\mathrm{s}], A_{j}$ is the surface area $\left[\mathrm{m}^{2}\right], c$ is the heat capacity of the air $\left[\mathrm{J} \mathrm{kg}^{-1} \mathrm{~K}^{-1}\right], n$ is the air change rate $\left[\mathrm{h}^{-1}\right], Q_{\text {sol }}$ is the heat flow due to the solar radiation [W], $Q_{i n}$ is the internal gains such as people, lights and equipment [W], $Q_{\text {vent }}$ is the heat flux gained or lost due to ventilation [W], $V$ is the volume $\left[\mathrm{m}^{3}\right]$.

The moisture balance can be described with the following equation

$$
\begin{aligned}
& V \frac{\partial v_{i}}{\partial t}=\sum_{j} A_{j} g_{i n, j}+M_{\text {prod. }}+M_{H V A C} \\
& +n \cdot V \cdot\left(v_{o}-v_{i}\right)+M_{v e n .}
\end{aligned}
$$

Where, $v_{o}$ is the vapor content of the exterior air $\left[\mathrm{kg} \mathrm{m}^{-3}\right], v_{i}$ is the vapor content of the interior air $\left[\mathrm{kg} \mathrm{m}^{-3}\right], g_{i n, j}$ is the moisture flux from the interior surface into the room $\left[\mathrm{kg} \mathrm{s}^{-1} \mathrm{~m}^{-2}\right], M_{\text {prod. }}$ is the moisture production $\left[\mathrm{kg} \mathrm{h}^{-1}\right], M_{v e n}$. is the moisture gains or losses due to the ventilation $\left[\mathrm{kg} \mathrm{h}^{-1}\right]$, $M_{H V A C}$ is the moisture gains or loss due to the HVAC system $\left[\mathrm{kg} \mathrm{h}^{-1}\right]$.

\section{Model validation}

International Energy Agency (IEA) has published a series of test suites for the validation of whole building energy simulation, which mainly include: IEA BESTEST (1995), IEA HVAC - BESTEST (2000), and IEA ECBCS Annex 21 / SHC Task 12 etc. Recently, IEA Annex 41 has added many analysis of the indoor and building envelope moisture conditions for the BESTEST building used in IEA ECBCS Annex 21 / SHC Task 12. These published testing tools are used to validate the present model. Comprehensive testing and verifications have been carried out. The result of experimental validation is presented in the paper.

The measurements were carried out in Frauhofer -Institut Fur Bauphysik, Germany. The test rooms have a floor area of $20 \mathrm{~m}^{2}$ and a volume of $50 \mathrm{~m}^{3}$. The external walls consist of $240 \mathrm{~mm}$ thick brick masonry with $100 \mathrm{~mm}$ exterior insulation. Walls and ceiling of the rooms are coated with $12 \mathrm{~mm}$ standard interior plaster. The double-glazed windows are facing south. The rooms are equipped with calibrated heating, ventilation and moisture production systems. Temperature sensors and heat flux meters are also fixed to the interior surface of external walls. The tests are performed with a constant air change rate $(\mathrm{ACH})$ of $0.5 \mathrm{~h}^{-1}$. A basic moisture production rate of $0.5 \mathrm{~g} \mathrm{~m}^{-3} \mathrm{~h}^{-1}$ is assumed with peaks in the morning and in the evening $\left(8 \mathrm{~g} \mathrm{~m}^{-3} \mathrm{~h}^{-1}\right.$ from 6:00 to 8:00 a.m. and $4 \mathrm{~g}$ 
$\mathrm{m}^{-3} \mathrm{~h}^{-1}$ from 4:00 to 10:00 p.m. every day). Detailed descriptions of the experimental set-up can be found in IEA Annex 41 report $^{[3]}$.

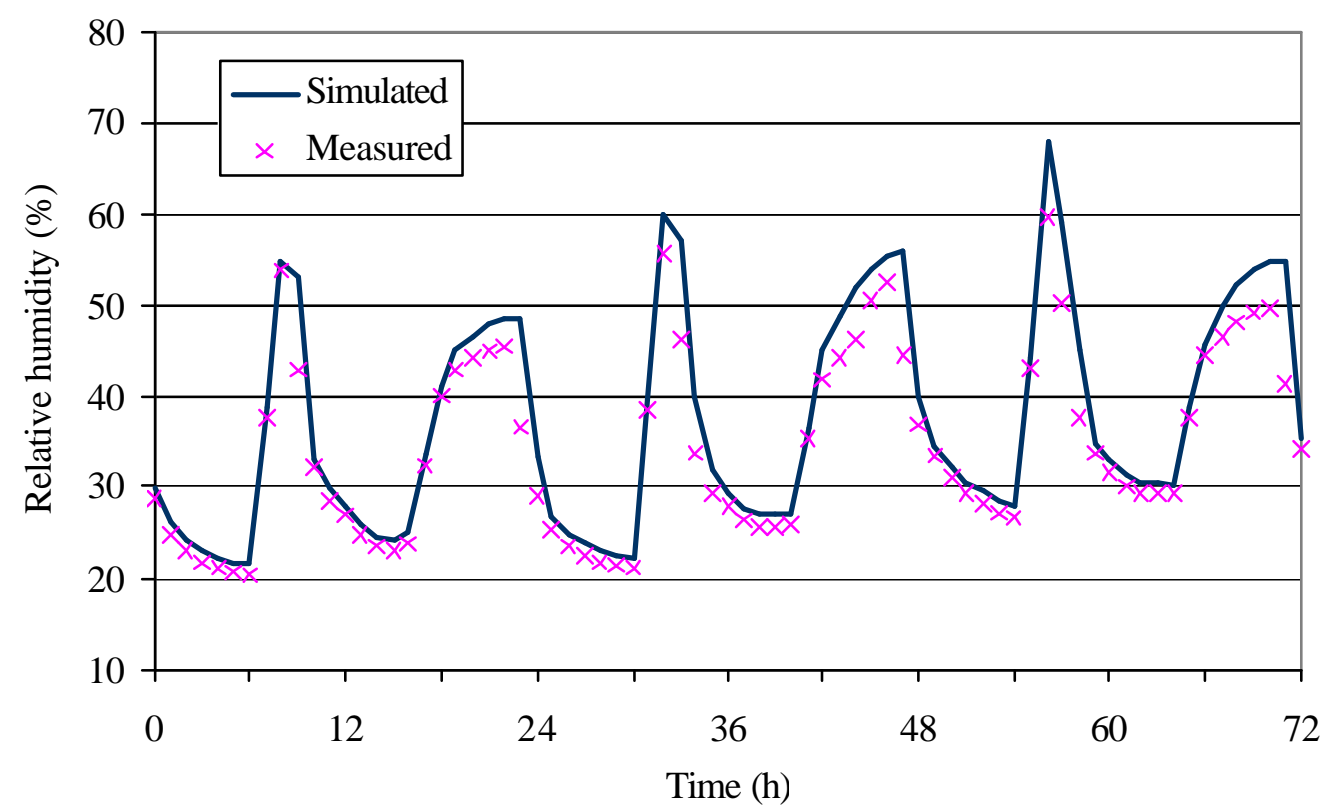

Fig. 1 The comparison of simulated results with the measured data (17 Jan. 2005 - 19 Jan. 2005)

Fig. 1 shows that the calculated indoor relative humidity is slightly larger than the measured data. It is assumed that the moisture buffering effect of the envelope retards the dynamic equilibrium in the experiment. Nevertheless, a considerably good agreement is found between the predicted results and the measures values. Consequently, it shows that the model presented above with a developed computer program is capable of simulating the whole building heat and moisture transfer.

\section{Model applications}

After being validated, the model is applied to investigate the moisture transfer effect on indoor air humidity and building energy consumption. The test room used for the experimental validation is assumed to be transferred to Shanghai, China where it serves as a typical hotel room. The room is occupied during the night time from 8:00 p.m. to 8:00 a.m. next day; and unoccupied the rest of the day. When the room is occupied, there is an interior heat and moisture production rate of $500 \mathrm{~W}$ and $3 \mathrm{~g} \mathrm{~m}^{-3} \mathrm{~h}^{-1}$ respectively. During the unoccupied period, the interior heat production decreases to 120 $\mathrm{W}$ and the moisture production decreases to $0.5 \mathrm{~g} \mathrm{~m}^{-3} \mathrm{~h}^{-1}$. The set-points of working temperature and relative humidity for the air-conditioning system are $24{ }^{\circ} \mathrm{C}$ and $60 \%$ respectively. The AC system only works during the occupied period. 


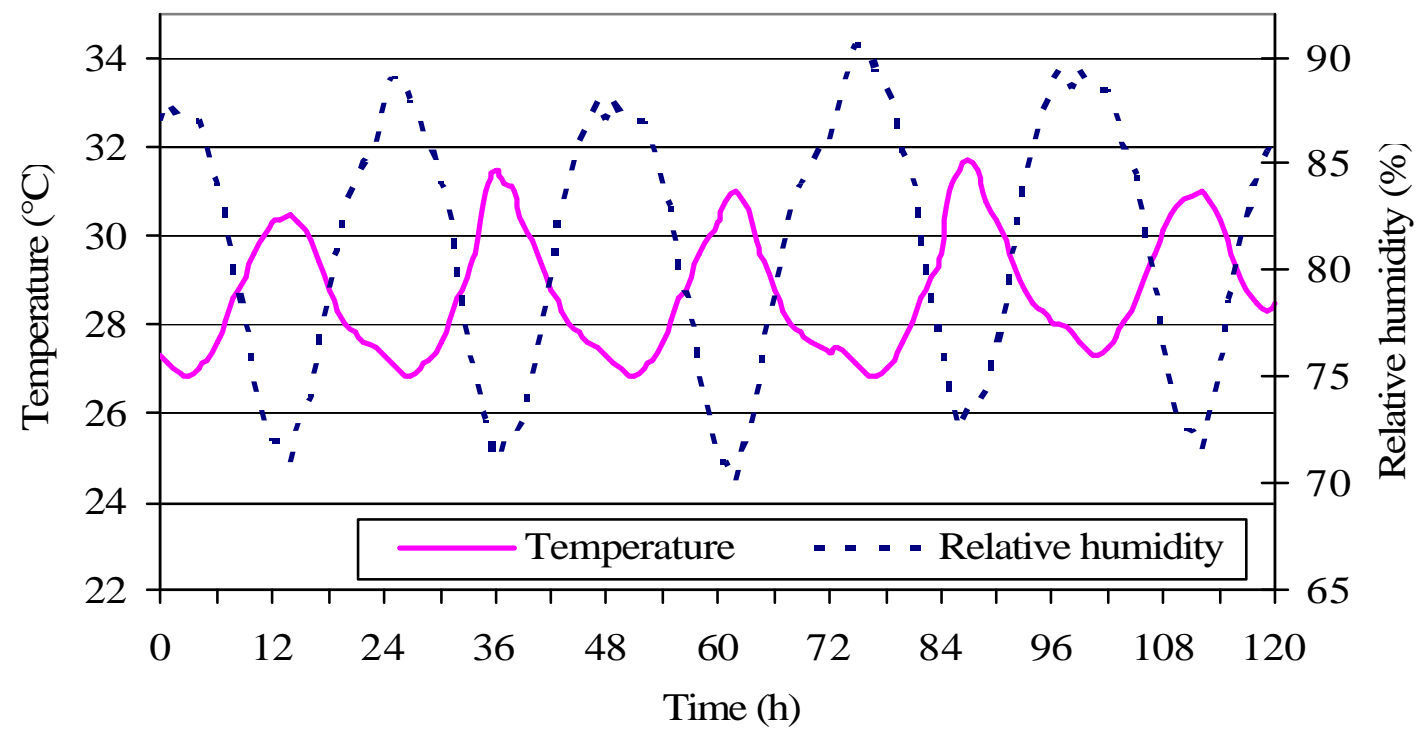

Fig. 2 Outdoor air temperature and relative humidity in Shanghai during 5 days in June

The simulated indoor temperature and relative humidity with or without taking into account the whole building moisture transfer are presented in Figs. 3 and 4. The results reveal that moisture transfer through the building envelope and vapor sorption-desorption at the interior wall surface have a great effect on the indoor relative humidity. In the case that includes these phenomena, the indoor relative humidity stays below $75 \%$ during the shut-off period of air-conditioning system. However, in the case without taking into account these phenomena, the maximum indoor relative humidity exceeds $80 \%$. The high indoor humidity will dramatically increase the risk of mold formation. An extra dehumidification procedure should be used. Furthermore, Fig. 4 shows that the indoor air temperature is nearly the same for both cases. This means the moisture transfer in the building construction has a significant influence on the latent cooling load while does not affect the sensible cooling load too much.

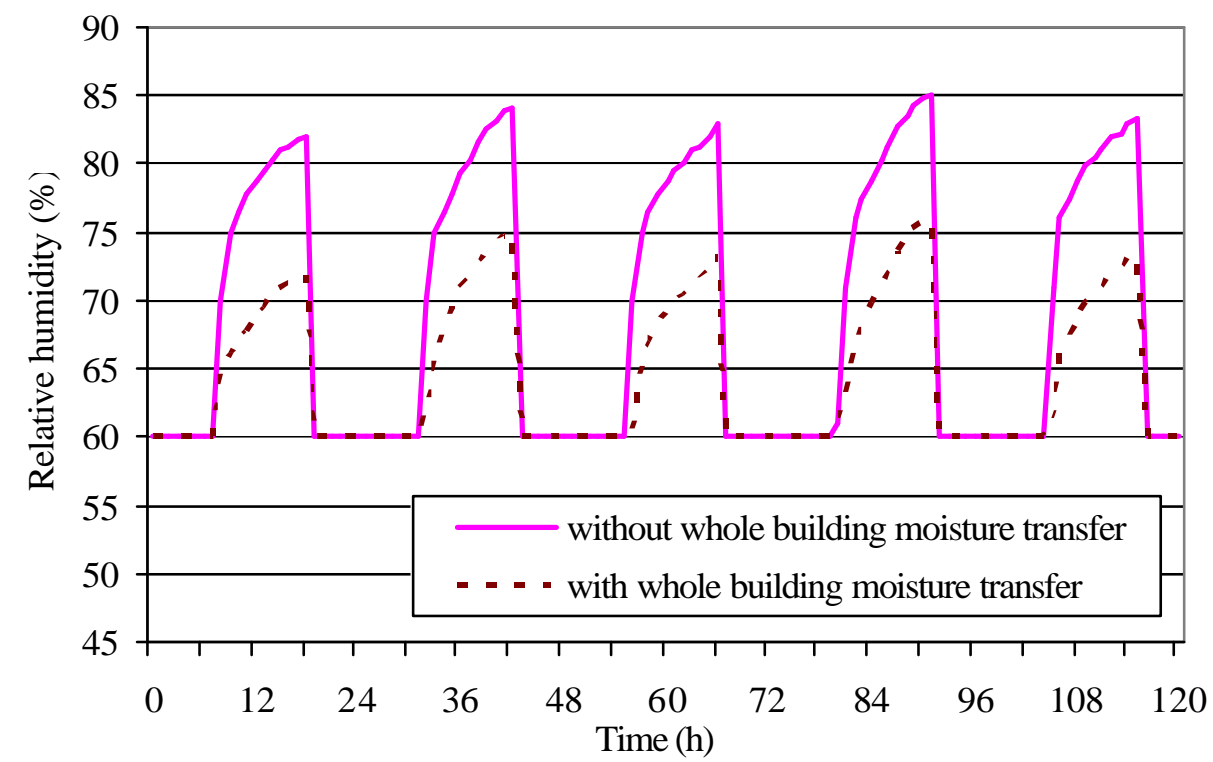

Fig. 3 Simulated indoor relative humidity 


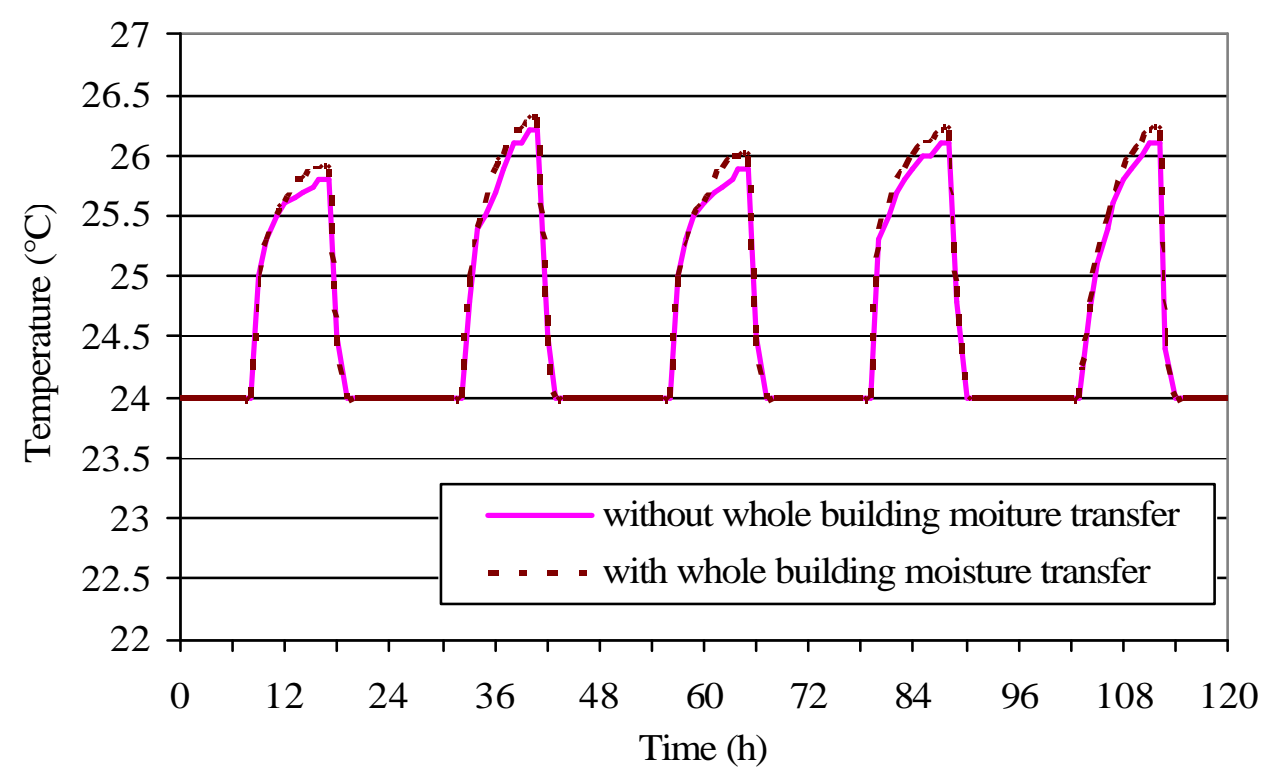

Fig. 4 Simulated indoor temperature

\section{Conclusions}

The coupled heat and moisture transfer in building envelopes has an important influence on the indoor air humidity and the overall performance of air-conditioned buildings. In the paper, a model for predicting the whole building heat moisture transfer was developed. The new model was validated by performing a series of testing and validation tools.

\section{References}

[1] QIN M. et al., An analytical method to calculate the coupled heat and moisture transfer in building materials, Int. Comm. in Heat and Mass Transfer 33(2006) 39-48.

[2] HAGENTOFT, C.E., Introduction to Building Physics, Studentlitteratur, Lund, Sweden.

[3] KRISTIN L. et al., IEA Annex 41-Subtask 1, Common Exercise, 2006. 